\title{
Questes
}

\section{Trouver la paix : conclusion}

\section{Stéphanie Richard et Irène Strobbe}

\section{(2) OpenEdition}

\section{Journals}

Édition électronique

URL : http://journals.openedition.org/questes/1360

DOI : 10.4000/questes. 1360

ISSN : 2109-9472

\section{Éditeur}

Les Amis de Questes

\section{Édition imprimée}

Date de publication : 25 septembre 2013

Pagination : 127-129

ISSN : 2102-7188

\section{Référence électronique}

Stéphanie Richard et Irène Strobbe «Trouver la paix : conclusion », Questes [En ligne], 26 | 2013, mis en ligne le 01 janvier 2014, consulté le 22 septembre 2020. URL : http://journals.openedition.org/ questes/1360 ; DOI : https://doi.org/10.4000/questes.1360 


\section{Conclusion}

\section{Stéphanie RICHARD et Irène STROBBE}

Université Paris-Sorbonne (Paris IV)

A l'issue de ces trois séminaires, il semble bien difficile d'affirmer qu'au Moyen Âge, il était possible de trouver la paix. Dans les faits, cette dernière apparaît comme un processus plutôt que comme un état. Les articles proposés dans ce recueil, s'inscrivant dans la lignée des recherches les plus récentes, attestent, chacun à leur manière, l'intérêt de la question.

$\mathrm{La}$ dimension pluridisciplinaire et l'aspect pluriscalaire des approches ont montré une fois de plus, si cela s'avérait encore nécessaire, qu'au Moyen Âge, la paix ne se laisse pas facilement enfermer dans des cadres d'études trop réducteurs. Pluridisciplinarité, d'abord : c'est sans doute là l'un des intérêts les plus manifestes de ces trois séminaires. Qu'il s'agisse d'évoquer la résolution des conflits entre les Gantois et leur seigneur naturel ${ }^{1}$, les ambassades de paix entre Grecs et Troyens ${ }^{2}$, le parlement des dames de Morée $^{3}$ ou encore la manière « pour tout le bas monde a paix traire » décrite par Christine de Pizan $^{4}$, l'on ne saurait en effet faire l'économie d'une analyse des discours - discours des personnages, discours de l'auteur même, et comparaison des différentes versions d'un même événement. Les échanges qui ont suivi les communications des jeunes chercheurs médiévistes nous ont permis d'aller plus loin dans l'étude des textes et des contextes.

\footnotetext{
${ }^{1}$ Voir l'article de Věra Vejrychová, supra, p. 49-65.

${ }^{2}$ Voir l'article de Marie Bedel, supra, p. 67-82.

${ }^{3}$ Voir l'article de Marie Guérin, supra, p. 35-48.

${ }^{4}$ Voir l'article de Sarah Delale, supra, p. 83-102.
} 
Multiplicité et enchâssement des échelles de travail, ensuite. De la recherche de la paix entre deux peuples à celle, toute intérieure, d'une recluse ${ }^{5}$, en passant par l'étude des démarches menées entre corporations et leurs implications à l'échelle de la ville ${ }^{6}$, les présents articles témoignent de la nécessité d'un jeu sur les échelles. Elles soulignent ainsi combien le consensus et la stabilité ne peuvent être trouvés que par des esprits et des cœurs libérés de leurs maux, que ce soit dans le cas d'une injustice réparée, d'un travail de deuil enfin accompli ou d'une volonté qui parvient à passer outre les obstacles qui s'opposaient à la conclusion de la paix. C'est Philippe le Hardi qui ignore l'orgueil des Gantois restés à cheval, c'est aussi Christine de Pizan qui surmonte la douleur du deuil sur le chemin de longue étude ; ce sont, a contrario, les Grecs et Troyens qui, ne parvenant pas à surmonter leur ubris, finissent par en payer le prix.

Diversité des acteurs, enfin. Princes, villes, corporations, humbles personnes en quête de paix pour eux-mêmes ou pour leurs pairs, voici exposés en six études des acteurs très différenciés. Il faut ici remarquer la place qui a été faite aux femmes dans ces communications. Il ne s'agissait pourtant en rien d'un axe de recherche proposé aux Questeurs. Lorsqu'elles ne sont pas à l'origine des tourments des hommes, comme c'est le cas d'Hésione et Hélène, les femmes apparaissent instigatrices ${ }^{7}$ et actrices de la paix ${ }^{8}$. Le constat n'en a donc que plus de force : quatre des six communications évoquent les liens qui unissent les femmes et la paix. Faut-il cependant s'en étonner? Aux côtés des hommes, les épouses, les sœurs et les filles sont souvent dépositaires de leurs pouvoirs en leur

\footnotetext{
${ }^{5}$ Voir l'article de Julie Pilorget, supra, p. 103-118.

${ }^{6}$ Voir l'article de Laure Gevertz, supra, p. 19-34.

${ }^{7}$ Voir l'article de Marie Guérin, supra, p. 35-48.

${ }^{8}$ Voir le rôle de l'épouse de Philippe le Hardi dans les négociations de paix avec les Gantois dans l'article de Věra Vejrychová, ou celui des recluses dans l'article de Julie Pilorget.
} 
absence, lorsqu'elles n'ont pas, en tant que compagnes présentes, une influence forte sur ceux-ci.

Il n'a pas non plus été fait l'économie de l'étude des processus de paix et, parfois, de leurs rituels. Ces derniers ont une place prépondérante dans la résolution de nombreux conflits, comme c'est le cas chez les artisans londoniens. Toutefois, il apparaît à l'aune de ce recueil que la paix ne peut se trouver, parfois, qu'en-dehors des sentiers battus et bien connus. Les cas étudiés évoquent pour la plupart une résolution hors norme des conflits. Avec les Gantois, seule l'attitude conciliante du prince, dont la clémence est sans doute attendue, permet de mettre fin aux hostilités, tandis que les bourgeois restent couverts devant leur seigneur. Le rôle des femmes dans la principauté de Morée semble lui aussi sortir de l'ordinaire. Si la paix paraît donc parfois se trouver en-dehors des processus de recherche habituels, encore faudrait-il pouvoir mesurer jusqu'à quel point, pour atteindre cette haute fin, les acteurs sont prêts à transiger avec les normes. On le voit, ce volume intitulé «Trouver la paix » aura sans doute soulevé plus de questions qu'il n'aura apporté de réponses, mais d'autres après nous s'attacheront peut-être à poursuivre l'enquête. 